\title{
Flavones, Flavonols, and Glycosylated Derivatives-Impact on Candida albicans Growth and Virulence, Expression of CDR1 and ERG11, Cytotoxicity
}

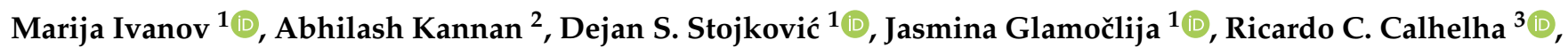 \\ Isabel C. F. R. Ferreira ${ }^{3}$ (D), Dominique Sanglard ${ }^{2}$ and Marina Soković $1, * \mathbb{D}$ \\ 1 Department of Plant Physiology, Institute for Biological Research "Siniša Stanković", \\ National Institute of Republic of Serbia, University of Belgrade, Bulevar Despota Stefana 142, \\ 11000 Belgrade, Serbia; marija.smiljkovic@ibiss.bg.ac.rs (M.I.); dejanbio@ibiss.bg.ac.rs (D.S.S.); \\ jasna@ibiss.bg.ac.rs (J.G.) \\ 2 Institute of Microbiology, University Hospital Lausanne and University Hospital Center, Rue du Bugnon 48, \\ 1011 Lausanne, Switzerland; abhilifescizurich@gmail.com (A.K.); dominique.sanglard@chuv.ch (D.S.) \\ 3 Centro de Investigação de Montanha (CIMO), Instituto Politécnico de Bragança, Campus de Santa Apolónia, \\ 5300-253 Bragança, Portugal; calhelha@ipb.pt (R.C.C.); iferreira@ipb.pt (I.C.F.R.F.) \\ * Correspondence: mris@ibiss.bg.ac.rs
}

Citation: Ivanov, M.; Kannan, A.; Stojković, D.S.; Glamočlija, J.; Calhelha, R.C.; Ferreira, I.C.F.R.; Sanglard, D.; Soković, M. Flavones, Flavonols, and Glycosylated Derivatives-Impact on Candida albicans Growth and Virulence, Expression of CDR1 and ERG11, Cytotoxicity. Pharmaceuticals 2021, 14, 27. https://doi.org/10.3390/ ph14010027

Received: 9 December 2020 Accepted: 28 December 2020 Published: 30 December 2020

Publisher's Note: MDPI stays neutral with regard to jurisdictional clai$\mathrm{ms}$ in published maps and institutional affiliations.

Copyright: (C) 2020 by the authors. Licensee MDPI, Basel, Switzerland. This article is an open access article distributed under the terms and conditions of the Creative Commons Attribution (CC BY) license (https:// creativecommons.org/licenses/by/ $4.0 /)$.

\begin{abstract}
Due to the high incidence of fungal infections worldwide, there is an increasing demand for the development of novel therapeutic approaches. A wide range of natural products has been extensively studied, with considerable focus on flavonoids. The antifungal capacity of selected flavones (luteolin, apigenin), flavonols (quercetin), and their glycosylated derivatives (quercitrin, isoquercitrin, rutin, and apigetrin) along with their impact on genes encoding efflux pumps (CDR1) and ergosterol biosynthesis enzyme (ERG11) has been the subject of this study. Cytotoxicity of flavonoids towards primary liver cells has also been addressed. Luteolin, quercitrin, isoquercitrin, and rutin inhibited growth of Candida albicans with the minimal inhibitory concentration of $37.5 \mu \mathrm{g} / \mathrm{mL}$. The application of isoquercitrin has reduced C. albicans biofilm establishing capacities for $76 \%$, and hyphal formation by yeast. In vitro treatment with apigenin, apigetrin, and quercitrin has downregulated CDR1. Contrary to rutin and apigenin, isoquercitrin has upregulated ERG11. Except apigetrin and quercitrin $(90 \mu \mathrm{g} / \mathrm{mL}$ and $73 \mu \mathrm{g} / \mathrm{mL}$, respectively inhibited $50 \%$ of the net cell growth), the examined flavonoids did not exhibit cytotoxicity. The reduction of both fungal virulence and expression of antifungal resistance-linked genes was the most pronounced for apigenin and apigetrin; these results indicate flavonoids' indispensable capacity for further development as part of an anticandidal therapy or prevention strategy.
\end{abstract}

Keywords: flavonoids; isoquercitrin; antifungal; biofilm; antivirulence; efflux pumps; cytotoxicity

\section{Introduction}

Candida albicans is nowadays recognized as one of the most common human pathogens. Its significance as a serious health as well as economic burden is a consequence of high mortality rates $(>70 \%)$ in some groups of patients, mainly immunocompromised [1]. Yeast C. albicans is the predominant cause of vulvovaginal candidiasis, a disease affecting up to $75 \%$ of women once in a lifetime [2], as well as oral candidiasis [3] and the prevalent healthcare-associated invasive fungal infection-invasive candidiasis [4]. Besides posing a serious threat to human health it is also the causative agent of animal skin infections [5].

This opportunistic fungus has developed a wide network of adaptations in order to survive and spread throughout human organism. It can group into biofilms, transit between yeast and hyphal morphology, and produce hydrolytic enzymes [6]. On the other hand, C. albicans also uses certain adaptation traits, including increased expression of CDR1 
and ERG11 genes, to avoid elimination by antifungal therapeutics [7]. All of the abovementioned traits have contributed to the medical significance of this pathogen-C. albicans is worldwide listed as one of the most common causes of human fungal infections with around 700,000 cases of invasive and 2,000,000 cases of oral candidiasis recorded annually [8]. The extensive usage of current first line antifungals is being linked to different side effects, including hepatotoxicity and nephrotoxicity, along with increased frequency of strains resistant to this type of treatment [9], urging the development of novel therapies.

Natural products have been extensively studied — at first in order to find agents that could inhibit growth of pathogenic microorganisms, but recently attention is focused on the role of natural products as inhibitors of virulence and quorum quenching agents [10]. Biological activities of numerous medicinal plants and foods are linked to abundant presence of flavonoids as bioactive principles. Besides well-known antioxidant properties of these molecules, there have been also studies regarding their antifungal potential. However, despite numerous researches in this field, mechanisms of antifungal activities as well as antivirulence properties of flavonoids remain mainly unrevealed [11].

The following study addressed anti-candidal activity of selected flavonoids: Flavone aglycones (luteolin, apigenin), a flavone glycosylated derivative (apigetrin), flavonol (quercetin), and its glycosylated derivatives (quercitrin, isoquercitrin, rutin). These molecules are present ubiquitously within plant kingdom and this study aimed to provide an insight into their antifungal potential with special focus on antivirulence properties along with impact on resistance linked genes expression as promising novel antifungal strategies.

\section{Results}

\subsection{Antifungal Potential of Selected Flavonoids}

The best antifungal potential among the tested compounds could be observed for luteolin, quercitrin, isoquercitrin, and rutin (minimum inhibitory concentration (MIC) $37.5 \mu \mathrm{g} / \mathrm{mL}$ ) (Table 1). Apigenin and apigetrin were the subject of a previous study by our group [12], and additional insight into their anticandidal activities has been enlightened within this study. Previously published active concentrations of apigenin (MIC $100 \mu \mathrm{g} / \mathrm{mL}$ ) and apigetrin (MIC $50 \mu \mathrm{g} / \mathrm{mL}$ ) towards the strain C. albicans 475/15 [12] were used in further experiments.

Table 1. Antifungal activity of tested flavonoids, values are means $\pm \mathrm{SD}$ in $\mu \mathrm{g} / \mathrm{mL}$ of three replicates. Different letters $(a, b, c, d)$ in each column indicate a significant statistical difference between the samples $(p<0.05)$. Minimum inhibitory concentration (MIC) and minimum fungicidal concentration (MFC) values of the compounds are compared separately for each of the fungal strain tested.

\begin{tabular}{|c|c|c|c|c|c|c|c|c|}
\hline \multirow{2}{*}{ Compounds } & \multicolumn{2}{|c|}{ C. albicans $475 / 15$} & \multicolumn{2}{|c|}{ C. albicans $527 / 14$} & \multicolumn{2}{|c|}{ C. albicans 10/15 } & \multicolumn{2}{|c|}{ C. albicans $13 / 15$} \\
\hline & MIC & MFC & MIC & MFC & MIC & MFC & MIC & MFC \\
\hline Luteolin & $37.5 \pm 1^{\mathrm{c}}$ & $75 \pm 2^{c}$ & $37.5 \pm 1^{\mathrm{c}}$ & $75 \pm 20^{c}$ & $37.5 \pm 1^{\mathrm{c}}$ & $75 \pm 2^{c}$ & $37.5 \pm 1^{\mathrm{c}}$ & $75 \pm 2^{c}$ \\
\hline Quercetin & $75 \pm 2^{d}$ & $150 \pm 10^{\mathrm{d}}$ & $75 \pm 2^{d}$ & $150 \pm 10^{d}$ & $75 \pm 3^{d}$ & $150 \pm 20^{d}$ & $75 \pm 10^{d}$ & $150 \pm 20^{d}$ \\
\hline Quercitrin & $37.5 \pm 2^{c}$ & $75 \pm 3^{c}$ & $37.5 \pm 2^{c}$ & $75 \pm 3^{c}$ & $37.5 \pm 2^{c}$ & $75 \pm 3^{c}$ & $37.5 \pm 1^{\mathrm{c}}$ & $75 \pm 3^{c}$ \\
\hline Isoquercitrin & $37.5 \pm 1^{\mathrm{c}}$ & $75 \pm 2^{c}$ & $37.5 \pm 1^{c}$ & $75 \pm 2^{c}$ & $37.5 \pm 2^{c}$ & $75 \pm 2^{c}$ & $37.5 \pm 2^{c}$ & $75 \pm 2^{c}$ \\
\hline Rutin & $37.5 \pm 1^{\mathrm{c}}$ & $75 \pm 1^{c}$ & $37.5 \pm 1^{\mathrm{c}}$ & $75 \pm 1^{c}$ & $37.5 \pm 1^{\mathrm{c}}$ & $75 \pm 2^{c}$ & $37.5 \pm 1^{\mathrm{c}}$ & $75 \pm 2^{c}$ \\
\hline Ketoconazole & $3.1 \pm 0.1^{\mathrm{b}}$ & $6.2 \pm 0.1^{b}$ & $3.1 \pm 0.1^{b}$ & $6.2 \pm 0.1^{b}$ & $3.1 \pm 0.1^{b}$ & $50 \pm 0.1^{b}$ & $1.6 \pm 0.2^{b}$ & $50 \pm 0.2^{b}$ \\
\hline Amphotericin B & $0.63 \pm 0.001^{a}$ & $1.25 \pm 0.002^{\mathrm{a}}$ & $0.63 \pm 0.001^{a}$ & $1.25 \pm 0.002^{\mathrm{a}}$ & $0.63 \pm 0.001^{a}$ & $1.25 \pm 0.002^{\mathrm{a}}$ & $0.63 \pm 0.001^{\mathrm{a}}$ & $1.25 \pm 0.002^{\mathrm{a}}$ \\
\hline
\end{tabular}

MIC - minimal inhibitory concentration, MFC — minimal fungicidal concentration.

\subsection{Interference of Tested Flavonoids with C. albicans Biofilm Formation}

All of the tested compounds exhibited some ability to act as biofilm formation inhibitors, especially when applied in concentrations equal to MIC or MIC/2. The most promising effect at MIC concentrations could be noticed for isoquercitrin (76\% inhibition) while both apigetrin and isoquercitrin applied in MIC/2 were able to prevent biofilm formation $>60 \%$. On the other hand, application of quercitrin and rutin MIC reduced formation of biofilms for less than $50 \%$ (Figure 1 ). 


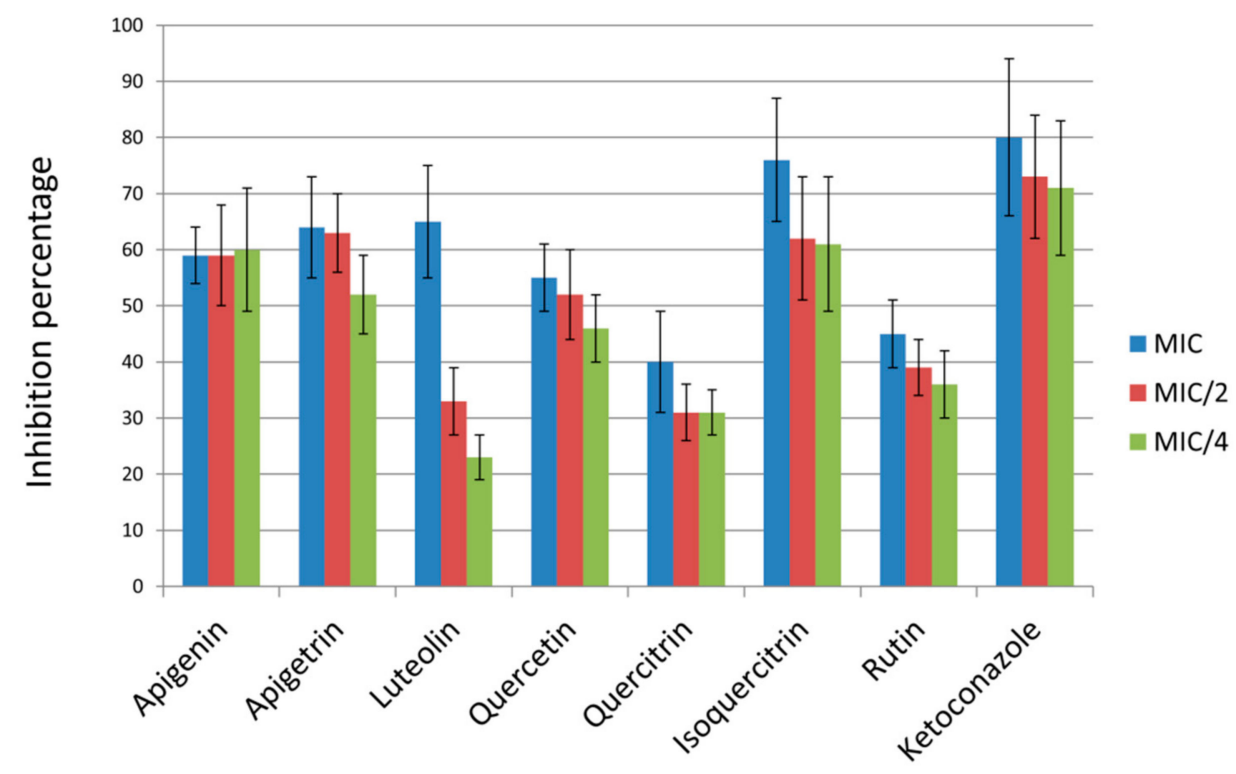

Figure 1. Percentage of inhibition of C. albicans biofilm formation after treatment with MIC and subMICs (MIC/2 and MIC/4) of compounds. Values are means \pm SD of three replicates.

\subsection{Flavonoids as Inhibitors of C. albicans Hyphal Growth}

The examined flavonoids have mainly shown moderate activity in the terms of reducing fungal hyphal growth (Figure 2). Treatment of $C$. albicans cells with both apigetrin and its aglycone apigenin has led to the lowest number of cells growing in the hyphal form (Figure 2). These two flavones have, in a previous experiment, reduced biofilm formation for more than 50\% implying their overall great potential for reduction of fungal virulence capacity. Isoquercitrin has also been efficient in reduction of hyphal growth, and since it had lower MIC values than apigenin and apigetrin [12], this activity has been accomplished in the lowest concentration among the tested molecules.

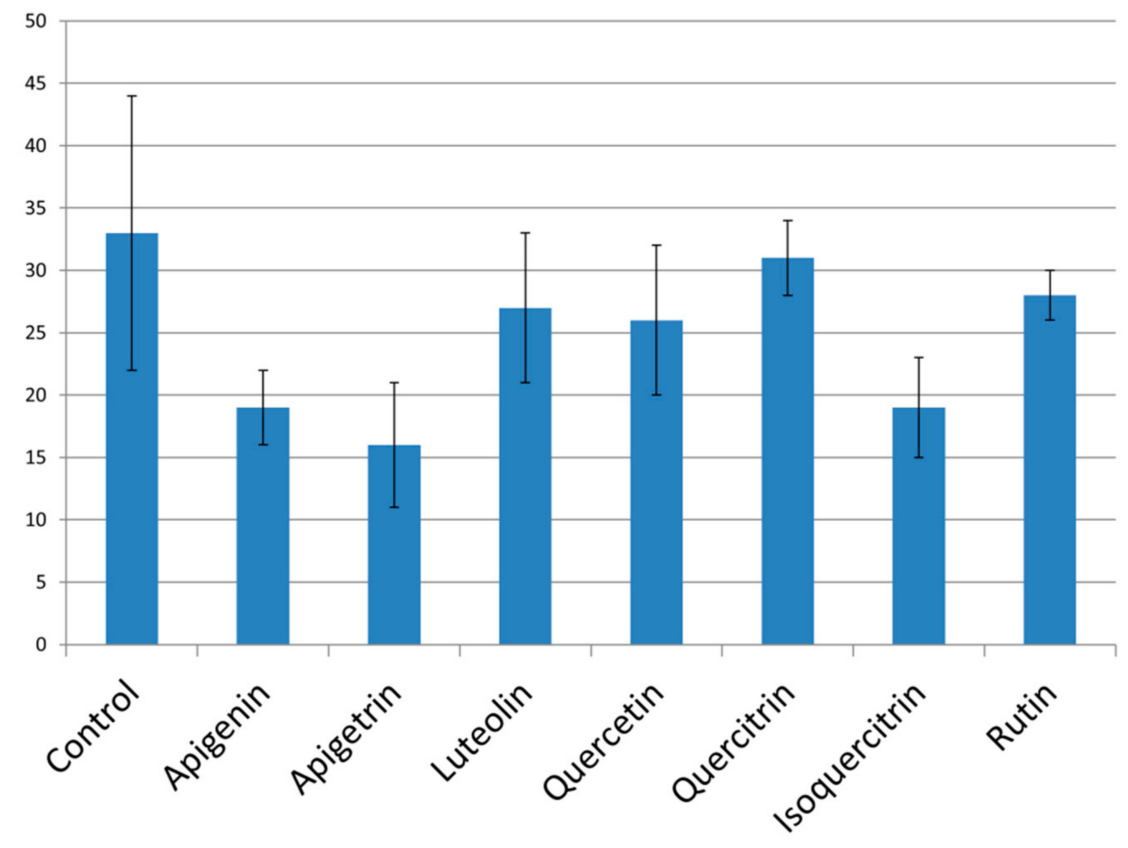

Figure 2. Percentage of hyphal cells calculated by comparison with the total number of C. albicans cells. Values are means \pm SD of three replicates. 


\subsection{Expression of Antifungal Resistance Associated Genes after Application of Flavonoids}

Treatment of $C$. albicans cells with selected flavonoids led to a more-or-less significant reduction of $C D R 1$ expression levels. Apigenin and apigetrin exhibited the most prominent impact on lowering $C D R 1$ levels $(\log 2 \mathrm{FC}<-1)$, while the effect of other flavonoids was less profound (Figure 3).

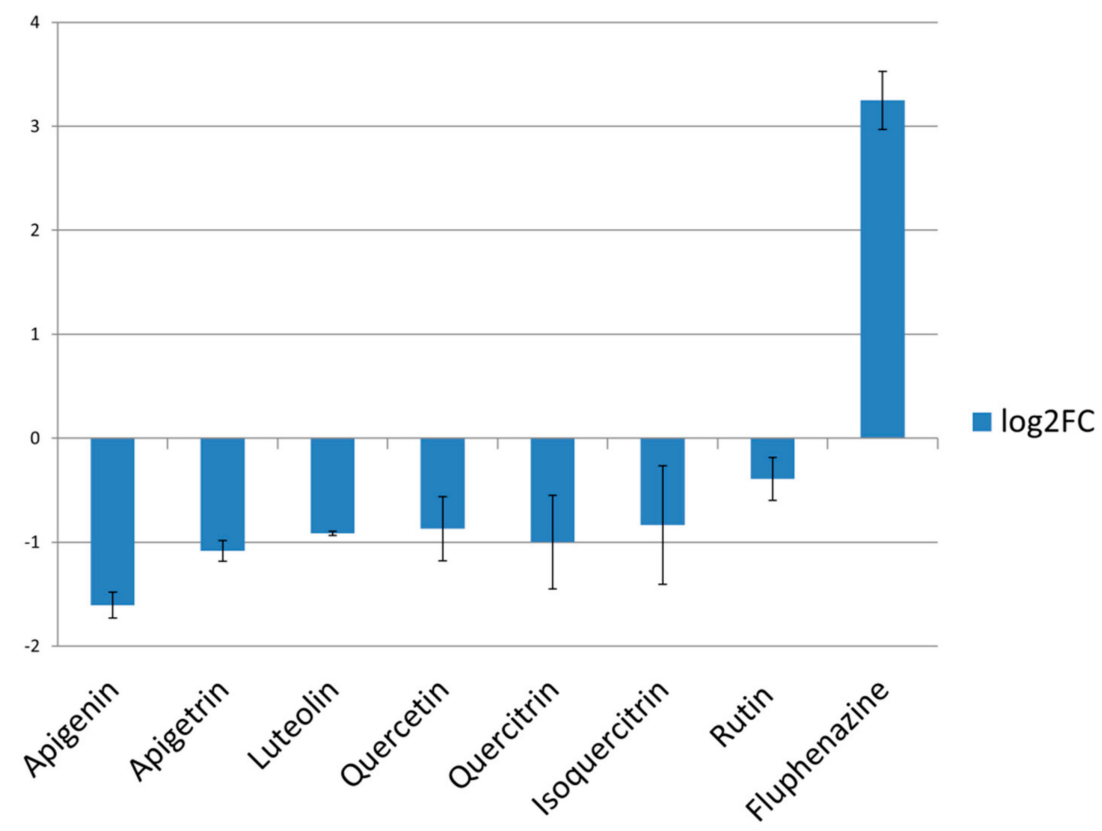

Figure 3. Expression levels CDR1 after treatment of MIC of compounds. Fluphenazine was used as positive control. Values are expressed as $\log 2$ fold changes ( $\log 2 \mathrm{FC}$ ) of Relative Quantification (RQ) values, averages of two biological replicates.

Treatment with isoquercitrin has up-regulated expression of ERG11 in C. albicans cells ( $\log 2 \mathrm{FC}>1)$, an undesirable trait of potential antifungals since their application can lead to reduced susceptibility to azole antifungals. Treatment of $C$. albicans with apigenin and rutin led to lower expression levels of ERG11 (Figure 4), suggesting that these compounds have potential for further development as part of novel antifungal strategies.

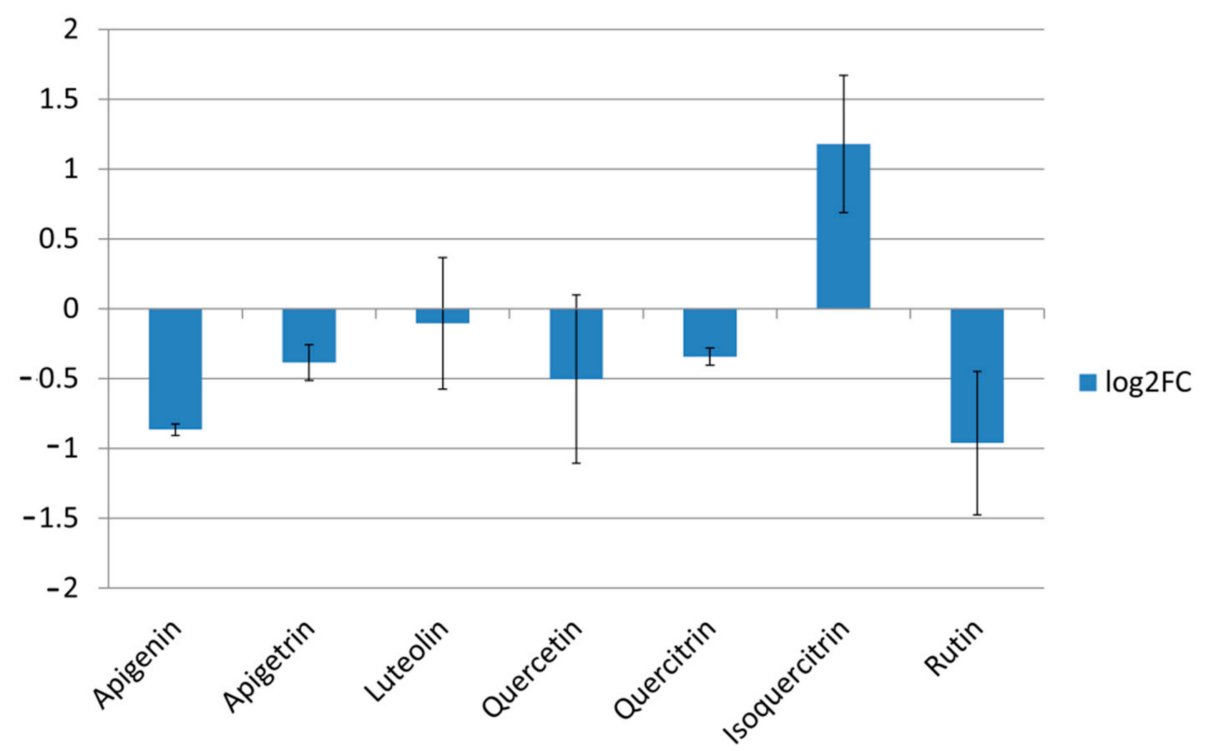

Figure 4. Expression levels of ERG11 after treatment of MIC of compounds. Values are expressed as $\log 2$ fold changes of RQ values, averages of two biological replicates. 


\subsection{Cytotoxicity of Selected Compounds}

Apigenin, luteolin, quercetin, isoquercitrin, and rutin did not exhibit cytotoxic effect towards porcine liver cells PLP2 (Table 2). On the other hand, apigetrin and quercitrin induced cytotoxicity at $\mathrm{GI}_{50} 90 \mu \mathrm{g} / \mathrm{mL}$ and $73 \mu \mathrm{g} / \mathrm{mL}$, respectively.

Table 2. Cytotoxicity of tested compounds, $\mathrm{GI}_{50}$ (compound concentration that inhibited $50 \%$ of the net cell growth) expressed in $\mu \mathrm{g} / \mathrm{mL}$.

\begin{tabular}{cc}
\hline Compound & $\mathbf{G I}_{\mathbf{5 0}}$ \\
\hline Apigenin & $>400$ \\
Apigetrin & $90 \pm 1$ \\
Luteolin & $>400$ \\
Quercetin & $>400$ \\
Quercitrin & $73 \pm 3$ \\
Isoquercitrin & $>400$ \\
Rutin & $>400$ \\
Ellipticin & $3.22 \pm 0.2$ \\
\hline
\end{tabular}

\section{Discussion}

Previous studies [13-15] have suggested less promising antifungal activity of luteolin towards different C. albicans strains (MIC $3.1 \mathrm{mg} / \mathrm{mL}$, MIC $>83 \mu \mathrm{g} / \mathrm{mL}$, and $>1 \mathrm{mg} / \mathrm{mL}$, respectively) compared to $37.5 \mu \mathrm{g} / \mathrm{mL}$ in this study (Table 1). Although quercetin in our study exhibited MIC $75 \mu \mathrm{g} / \mathrm{mL}$ (Table 1), much better activity has been detected previously [16] (MIC $8 \mu \mathrm{g} / \mathrm{mL}$ towards C. albicans ATCC 10231). On the other hand, lower activity of quercetin was observed in previous studies: MIC $100 \mu \mathrm{g} / \mathrm{mL}$, C. albicans ATCC 10231 [17], MIC $>83 \mu \mathrm{g} / \mathrm{mL}$, clinical isolates, and C. albicans 10231 [14], and MIC 128-512 $\mu \mathrm{g} / \mathrm{mL}$, clinical isolates, and reference C. albicans strains ATCC 10231 and SC5314 [18]. The obtained information regarding excellent antifungal potential of the flavonol glycoside, quercitrin (MIC $37.5 \mu \mathrm{g} / \mathrm{mL}$ ) (Table 1), differs from studies by Gehrke et al. [17] and Sekita et al. [19] where MICs $100 \mu \mathrm{g} / \mathrm{mL}$ (towards C. albicans ATCC 10231) and $>512 \mu \mathrm{g} / \mathrm{mL}$ (C. albicans CAD1, clinical isolate), respectively, were found. Isoquercitrin in our study exhibited MIC $37.5 \mu \mathrm{g} / \mathrm{mL}$ (Table 1) while an earlier study [20] established much better antifungal potency with MIC $2.5 \mu \mathrm{g} / \mathrm{mL}$ towards C. albicans ATCC 90028. Rutin had excellent activity in inhibiting growth of C. albicans (MIC $37.5 \mu \mathrm{g} / \mathrm{mL}$, Table 1), while similar antimicrobial potential of this flavonoid has been determined previously [21], (MIC $40 \mu \mathrm{g} / \mathrm{mL}$ towards C. albicans ATCC 10231). Lower antimicrobial potential of rutin has been established in the studies by Han et al. [22] where $1000 \mu \mathrm{g} / \mathrm{mL}$ of rutin was necessary for C. albicans CA-1 growth inhibition and in the studies by Johann et al. [23] where it was claimed that rutin has insignificant antifungal potential (MIC $>1000 \mu \mathrm{g} / \mathrm{mL}$ ) when applied towards C. albicans ATCC 18804. There could be various reasons that led to manifested differences in antimicrobial potential of all the mentioned compounds. Among the many of potential reasons we could highlight differences in strains sensitivity since different strains of C. albicans were used in almost all referred studies. We could observe stronger antifungal activity of glycosylated flavonol derivatives (quercitrin, isoquercitrin, and rutin) compared to their aglycone, quercetin (MIC $37.5 \mu \mathrm{g} / \mathrm{mL}$ and $75 \mu \mathrm{g} / \mathrm{mL}$, respectively). Sugar moiety has also been highlighted as the reason for previously confirmed stronger antifungal effect of apigenin-7O-glycoside compared to its aglycone apigenin [12]. This superiority might be related to increased solubility and amphiphilicity recorded for glycosylated plant metabolites, which may enhance their membrane transport [24].

Apigenin in the previous study [25] did not show any antibiofilm effect when concentration $125 \mu \mathrm{g} / \mathrm{mL}$ was applied towards oral and reference C. albicans isolates (SC5314 and 3153A). On the other hand, another study [26] determined its high efficiency since only $5 \mu \mathrm{g} / \mathrm{mL}$ of this flavonoid was necessary for C. albicans ATCC 90028 biofilm reduction. Luteolin investigation [27] claimed that this flavonoid is inefficient towards C. albicans ATCC 90028 biofilm in much higher concentrations $(625-5000 \mu \mathrm{g} / \mathrm{mL})$ than 
examined in our study $(9.38-37.5 \mu \mathrm{g} / \mathrm{mL})$. The impact of quercetin on C. albicans NBC099 biofilms was studied earlier [28] but in this investigation, quercetin was applied in a much higher concentration that prevented biofilm establishment $(200 \mu \mathrm{g} / \mathrm{mL}$ compared to $18.75-75 \mu \mathrm{g} / \mathrm{mL}$ in our study). Other studies have examined impact of this flavonol on preformed C. albicans ATCC 90028 biofilms-a concentration of $625 \mu \mathrm{g} / \mathrm{mL}$ was inactive against 24-h-old biofilms [27]. Lower antibiofilm activity of quercetin has been observed by determination of SMIC (sessile cells MIC); SMIC > $200 \mu \mathrm{g} / \mathrm{mL}$ (oral and reference C. albicans isolates (SC5314 and 3153A, [25]) and SMIC $\geq 1024 \mu \mathrm{g} / \mathrm{mL}$ (C. albicans ATCC 10231, SC 5314, and clinical isolates, [18]). Cells in the established biofilms are more resistant to antifungal treatment [29] so this might be the reasons for determined high SMICs. Further insight into antibiofilm potential of quercetin has been provided in the study by Gao et al. [18] where it was observed that treatment with this flavonoid leads to reduced ALS1, ALS3 (Agglutinin Like Sequence gene family), HWP1 (Hyphal Wall Protein), and SUN41 (gene encoding for secreted beta-glucosidase) expression levels. Quercitrin had the lowest potential to reduce biofilm formation among all the flavonoids tested in our study (Figure 1) with its complete lack of activity towards C. albicans CAD1 biofilm observed previously [19]. On the other hand, excellent activity on inhibition of C. albicans biofilm formation was addressed to another flavonol glycoside, isoquercitrin (tested concentration 9.38-37.5 $\mu \mathrm{g} / \mathrm{mL}$ ) (Figure 1) with a previous study [19] highlighting its antibiofilm potential in higher concentration-200 $\mathrm{gg} / \mathrm{mL}$. Rutin was among the natural compounds with the lowest activity against biofilm formation in this study (Figure 1) with its lack of C. albicans CAD1 antibiofilm activity also observed earlier [19]. Overall, glycoside derivatives, apigetrin and isoquercitrin, have shown more promising antibiofilm potential compared to their corresponding aglycones. The superior antibiofilm potential of isoquercitrin compared to the other quercetin glycosides examined (quercitrin and rutin) suggests that biological activity is strongly enhanced by beta-D-glucosyl residue compared to alpha-L-rhamnosyl moiety (quercitrin) and 3-O-rutinoside (rutin). A recent study [30] indicated rutin as the least active quercetin derivative, which is by some extent confirmed in the antibiofilm and antihyphal assays in our study, especially in comparison with isoquercitrin. The less promising antibiofilm potential of quercitrin and rutin, compared to isoquercitrin, might be linked to their higher lipophilicity since the increased lipophilicity might reduce membrane-passing capability [30].

The strongest anti-hyphal potential was observed for apigetrin, a glycoside not studied before as inhibitor of this virulence trait, according to the author's best knowledge. On the other hand, the potential of quercetin to reduce formation of hyphae has been studied previously. Application of up to $200 \mu \mathrm{g} / \mathrm{mL}$ [28] and $64 \mu \mathrm{g} / \mathrm{mL}$ [18] of quercetin led to reduction of morphological transition of this yeast, while in our study, $75 \mu \mathrm{g} / \mathrm{mL}$ has induced only slight inhibition.

The inhibitory impact of two flavones, apigenin and apigetrin (Figure 3), along with previously published flavonol astragalin [31] on CDR1 expression should be further explored since their application might increase fungal susceptibility to current therapeutics due to reduction in cell efflux. Apigenin has been examined previously when applied $38 \mu \mathrm{g} / \mathrm{mL}$ inhibited bacterial efflux pumps [32]. Application of quercetin and luteolin caused S. aureus efflux inhibition with $\mathrm{IC}_{50} 75 \mu \mathrm{g} / \mathrm{mL}$ [32], while in our study, they did not exhibit any significant inhibitory potential towards CDR1 expression when applied in $75 \mu \mathrm{g} / \mathrm{mL}$ and $37.5 \mu \mathrm{g} / \mathrm{mL}$, respectively. Isoquercitrin treatment has increased expression levels of ERG11 (Figure 4) proposing potential negative interaction of this flavonoid with azole antifungals targeting enzyme CYP51 encoded by ERG11. Apigenin and rutin, due to their negative impact on ERG11 expression (Figure 4), might help in eradicating the infections caused by $C$. albicans strains resistant to azole drugs due to mutations that upregulate ERG11. These presumptions should be further investigated. As far as we know, none of these compounds have been tested earlier in order to examine their impact on ERG11 and $C D R 1$ expression; furthermore, their downregulating ability is of great interest especially 
bearing in mind the lack of ketoconazole, a widely used antifungal, and the impact on downregulation of CDR1 and ERG11 determined in the identical assay [31].

Previous study of apigenin claimed that it induces cytotoxicity mainly in the cancer cell lines [33]. Apigenin has exhibited cytotoxicity towards TIG-1 (human lung embryonic fibroblasts) and HUVE (human umbilical vein endothelial) cells ( $\left.\mathrm{LC}_{50} 110 \mu \mathrm{M}\right)$ [34] with $\mathrm{LC}_{50}$ value lower than apigenin MIC (Table 1) suggesting that despite its non-cytotoxicity towards PLP2 cells (Table 2) its cytotoxicity towards additional cell lines should be further explored. Glycoside of apigenin and apigetrin, showed some cytotoxic effect (Table 2) in concentrations higher than its average MICs [12]; meanwhile, previous study [35] demonstrated that apigetrin concentration up to $100 \mu \mathrm{M}$ does not induce cytotoxicity in 3T3-L1 pre-adipocytes. Luteolin in previous studies showed $\mathrm{LC}_{50} 107 \mu \mathrm{M}$ and $57 \mu \mathrm{M}$ towards TIG-1 and HUVE cells, respectively [34]. The study of luteolin effect on apoptosis of normal human peripheral blood mononuclear cells showed that it does not induce apoptosis in concentration tested $(20 \mu \mathrm{M})$ [36]. Quercetin did not exhibit cytotoxicity towards liver cells in our study, unlike in another study [34] where cytotoxicity towards HUVE cells was determined $\left(\mathrm{LC}_{50} 61 \mu \mathrm{M}\right)$. Quercetin glycoside, quercitrin, exhibited $\mathrm{GI}_{50}$ $73 \mu \mathrm{g} / \mathrm{mL}$ (Table 2), which is lower than its MFCs (Table 1) implying that side effects may arise as a consequence of quercitrin antifungal application. Another quercetin glycoside, isoquercitrin, did not show cytotoxic effects towards tested cells in this study (Table 2), as well as towards non-tumor colon cell (IEC-18) (up to $150 \mu \mathrm{M}$ concentration) [37]. Rutin did not show cytotoxic effect in our study (Table 2), which is in line with previous study on different cells [34].

\section{Materials and Methods}

\subsection{Fungal Culture Conditions}

C. albicans was isolated from oral cavities of patients at ENT Clinic, Clinical Hospital Centre Zvezdara, Belgrade, Serbia after obtaining informed written consent and identified by using CHROMagar plates (Biomerieux, Craponne, France). Strains were maintained on Sabouraud Dextrose Agar (Merck, Darmstadt, Germany) and are deposited at the Mycological Laboratory, Department of Plant Physiology, Institute for Biological Research "Siniša Stanković", National Institute of Republic of Serbia, University of Belgrade. The collection of samples was approved by the Ethical Committee (Office for Human Research Protection, Zvezdara University Medical Center, Belgrade, Serbia, document issued 26 October 2016).

\subsection{Antifungal Activity}

Microdilution assay [38] with some modification was used for determination of minimum inhibitory (MIC) and minimum fungicidal concentrations (MFC) [31]. Yeast cultures were adjusted to $1.0 \times 10^{5} \mathrm{CFU} /$ per well with sterile PBS (Phosphate buffered saline, $\mathrm{pH}$ 7.4). The 96-well microtiter plates with serially diluted flavonoids (concentration range $0.3-75 \mu \mathrm{g} / \mathrm{mL}$ ) in liquid broth were incubated at $37^{\circ} \mathrm{C}$ for $24 \mathrm{~h}$. After incubation, MIC and MFC were determined. The lowest concentrations that were not inducing microscopically observed growth were considered as MIC. For microscopic determination of growth, we used inverted microscope Nikon Eclipse TS2 (Amsterdam, Netherland) and examined the fungal growth in the wells of 96-well microtiter plates compared to the control (untreated yeast cells). MFC values were determined as concentrations without visible growth after serial sub-cultivation of $10 \mu \mathrm{L}$ of samples at $37^{\circ} \mathrm{C}$ for $24 \mathrm{~h}$. Ketoconazole and amphotericin B (SigmaAldrich, Darmstadt, Germany) were used as an antifungal control. The tested flavonoids were obtained from Extrasynthese, Rhone, France.

\subsection{Impact of Selected Compounds on Candida albicans Virulence Factors}

\subsubsection{Antibiofilm Activity}

Potential of selected compounds to interfere with C. albicans $475 / 15$ biofilm formation was investigated as previously described [39]. Briefly, C. albicans 475/15 was incubated with serial dilution of the compounds (MIC and subMICs) in YPD medium, in 96-well 
microtiter plates with adhesive bottom (Sarstedt, Nümbrecht, Germany), at $37{ }^{\circ} \mathrm{C}$ for $24 \mathrm{~h}$. After incubation, wells were washed twice with sterile PBS and methanol was added into each well. After fixation, methanol was discarded, and the plate was air dried. Formed biofilms were stained with $0.1 \%$ crystal violet (Bio-Merieux, Craponne, France) for $30 \mathrm{~min}$. The plate was gently washed under the tap of water and air dried. The stain bound to the remaining biofilms was dissolved with ethanol (96\%, Zorka, Šabac, Serbia). Absorbance was read on a Multiskan ${ }^{\mathrm{TM}}$ FC Microplate Photometer, Thermo Scientific ${ }^{\mathrm{TM}}$. The percentage of inhibition of biofilm formation was calculated by the formula:

$$
\text { [(A620control - A620sample)/A620control] } \times 100
$$

\subsubsection{Anti-Hyphal Forming Activity}

C. albicans $475 / 15$ cells were incubated with MIC of tested compounds in YPD $+10 \%$ FBS, at $37{ }^{\circ} \mathrm{C}$, for $4 \mathrm{~h}$. Cells were examined under microscope (Nikon Eclipse TS2, Amsterdam, Netherland) and number of cells, growing in the yeast or hyphal and germ tube formations, was determined. Assay was performed in triplicate and percentage of hyphae was determined.

\subsection{Interference with Expression of CDR1 and ERG11 \\ 4.4.1. RNA Isolation}

Total RNA was isolated as described by Sanglard et al. [40] with some modifications. C. albicans $475 / 15$ was grown with agitation at $30^{\circ} \mathrm{C}$ in YEPD until OD540 $=0.4$. C. albicans cells were incubated with MIC of compounds in YEPD at $30{ }^{\circ} \mathrm{C}$ with agitation for $30 \mathrm{~min}$. Cells were centrifuged (4600 rpm, $4{ }^{\circ} \mathrm{C}$ for $5 \mathrm{~min}$ (Rotanata $460 \mathrm{R}$, Hettich, Tuttlingen, Germany)) and the pellet was resuspended in $300 \mu \mathrm{L}$ of RNA buffer $(0.1 \mathrm{M}$ Tris- $\mathrm{HCl}$ pH 7.5, 0.1M LiCl, 10mM EDTA, 0.5\% SDS). The pellet was homogenized with $200 \mu \mathrm{L}$ of DEPC treated glass beads and $300 \mu \mathrm{L}$ of Phenol:Chloroform:Isoamyl Alcohol (Sigma-Aldrich, Darmstadt, Germany) in Precellys Evolution tissue homogenizer (Bertion instruments, Montigny-le-Bretonneux, France) at $4500 \mathrm{rpm}$ for $5 \mathrm{~s}$. After centrifugation $\left(14,000 \mathrm{rpm}, 4^{\circ} \mathrm{C}\right.$, 1 min (Universal 32 R, Hettich, Tuttlingen, Germany)) $200 \mu \mathrm{L}$ of supernatant was vortexed with $250 \mu \mathrm{L}$ of Phenol:Chloroform:Isoamyl Alcohol for $10 \mathrm{~s}$. Samples were centrifuged $\left(14,000 \mathrm{rpm}, 4^{\circ} \mathrm{C}, 1 \mathrm{~min}\right)$ and $200 \mu \mathrm{L}$ of supernatant was transferred to new tubes, $400 \mu \mathrm{L}$ of ice-cold $99 \%$ ethanol was added to each tube, and they were kept on dry ice for $10 \mathrm{~min}$. Samples were centrifuged (14,000 rpm, $\left.4{ }^{\circ} \mathrm{C}, 2 \mathrm{~min}\right)$, pellet was washed with ethanol $(70 \%)$, left to dry at room temperature, after which it was dissolved in $50 \mu \mathrm{L}$ of DEPC treated water. Nanodrop (ND-1000, Witec AG, Sursee, Switzerland) was used for determination of concentration and purity of samples. RNA was stored at $-80^{\circ} \mathrm{C}$.

\subsubsection{DNAse Treatment and cDNA Synthesis}

Amount of $10 \mu \mathrm{g}$ RNA was incubated with $5 \mu \mathrm{L}$ of DNAse buffer and $1 \mu \mathrm{L}$ of DNAse at $37^{\circ} \mathrm{C}$ for 30 min (DNA-free ${ }^{\mathrm{TM}}$ DNA Removal Kit, Ambion, Bleiswijk, Netherlands). After addition of DNAse inactivation reagent tubes were kept at room temperature with occasional vortexing for $5 \mathrm{~min}$. Samples were centrifuged $\left(14,000 \mathrm{rpm}, 4^{\circ} \mathrm{C}, 2 \mathrm{~min}\right)$ and the concentration and quality of supernatant were analyzed on Nanodrop (ND-1000, Witec AG, Sursee, Switzerland).

Synthesis of cDNA was done with a Transcriptor High Fidelity cDNA synthesis kit (Roche). RNA $(1 \mu \mathrm{g})$ was incubated with $60 \mu \mathrm{M}$ random hexamer primers, in $11.4 \mu \mathrm{L}$ of total sample volume, at $65^{\circ} \mathrm{C}$ for $10 \mathrm{~min}$. The mixture of Transcriptase reaction buffer $5 \times$, Deoxynucleotide mix, DTT, Protector RNAse inhibitor, and Transcriptor High Fidelity Reverse Transcriptase was added to each tube according to manufacturer instructions. Synthesis of cDNA was completed by incubating the mixture at $50{ }^{\circ} \mathrm{C}$ for $30 \mathrm{~min}$ and $85^{\circ} \mathrm{C}$ for 5 min (Peqstar thermocycler, Peqlab, Erlangen, Germany). 


\subsection{3. qPCR}

Wells of MicroAmp Fast $96-$ Well Reaction plate $((0.1 \mathrm{~mL})$, Applied biosystems, Waltham, MA, USA) were incubated with $10 \mu \mathrm{L}$ of mixture (cDNA, $2 \times$ MasterMix, primers, probe (Table 3), and water) [41]. Analysis was performed in StepOnePlus Real Time PCR system with relative standard curve method. Expression levels of CDR1 and ERG11 were normalized to expression of $A C T 1$.

Table 3. Sequences of TaqMan primers and probes used in qPCR.

\begin{tabular}{cc}
\hline Primer & Sequence \\
\hline CDR1-ORF-F & ATGACTCGAGATATTTTGATA \\
CDR1-ORF-R & TTAACAGCAATGGTCTTTA \\
ERG11-ORF-F & ATTGTTGAAACTGTCATTG \\
ERG11-ORF-R & CCCCTAATAATATACTGATCTG \\
ACT-ORF-F & GCATCACACTTTTTACAAT \\
ACT-ORF-R & AAACATAATTTGAGTCATCTTT \\
\hline Probe & Sequence \\
\hline CDR1-P2 & CATTATGAGACCTGGTGAACTTACT \\
ERG11-P2 & TTTGTCCCTTAGTGTTACACA \\
ACT1-P2 & TTGCTCCAGAAGAACATCCAGT \\
\hline
\end{tabular}

\subsection{Cytotoxicity of Compounds Towards Porcine Liver Primary Cells}

Preparation of PLP2 cell line was performed with freshly harvested porcine liver supplied from a local slaughter house. Tissues from the liver were washed in Hank's balanced salt solution comprising $100 \mathrm{U} / \mathrm{mL}$ penicillin and $100 \mu \mathrm{g} / \mathrm{mL}$ streptomycin and split into $1 \times 1 \mathrm{~mm}^{3}$ explants. Some of the prepared explants were set in $25 \mathrm{~cm}^{2}$ tissue flasks in Dulbecco's modified Eagle's medium (DMEM) with 10\% fetal bovine serum (FBS), $2 \mathrm{mM}$ nonessential amino acids, $100 \mathrm{U} / \mathrm{mL}$ penicillin, and $100 \mathrm{mg} / \mathrm{mL}$ streptomycin, and incubation was conducted at $37^{\circ} \mathrm{C}$ with $5 \% \mathrm{CO}_{2}$ in a humidified atmosphere. The fresh medium was added every 2 days. Cultivation of the cells was further conducted with direct observation by the phase contrast microscope every $2-3$ days. Before confluence was achieved, cells were subcultured and seeded in 96-well plates at a density of $1.0 \times 10^{4}$ cells per well and cultivated in DMEM supplemented with $10 \%$ FBS, $100 \mathrm{U} / \mathrm{mL}$ penicillin, and $100 \mu \mathrm{g} / \mathrm{mL}$ streptomycin. Previously described Sulforhodamine B assay [42] was used for the determination of cytotoxicity. The obtained results were defined as $\mathrm{GI}_{50}$ values corresponding to the compound concentration that inhibits $50 \%$ of the net cell growth. Ellipticine was used as a positive control.

\subsection{Statistical Analysis}

The antifungal results are expressed as mean values of three replicates and standard deviation (SD). The results were analyzed using one-way analysis of variance (ANOVA) followed by Tukey's HSD test with $\alpha=0.05$ using the SPSS v. 18.0 program. QPCR analysis was done in technical triplicates with the results presented as mean values of 2 biological replicates.

\section{Conclusions}

The lowest capacity against planktonic fungal cells indicated by the highest value of minimal inhibitory concentration was recorded for quercetin. Overall, the examined flavonoids have shown promising antifungal activity. The tested molecules, especially apigetrin and isoquercitrin, have notably lowered potential of Candida albicans to establish biofilm, with its antivirulence potential additionally emphasized by their anti-hyphal properties elucidating the potential of these natural products to be developed as antivirulence therapeutics. Another mode of antifungal therapy could also be based on lowering expression of resistance linked genes by providing elimination of candidiasis with lower 
concentrations of current therapeutics. In this manner, the activity of apigenin and apigetrin (lowering CDR1 expression) and apigenin and rutin (lowering ERG11 expression) is of great importance. On the other hand, undesirable activity was recorded for isoquercitrin (increased ERG11 expression). All of the studied flavonoids, with the exception of quercitrin, were able to exhibit in vitro fungicidal effects in concentrations that were not cytotoxic indicating them as promising antifungal candidates.

The obtained results confirm great biological potential among the molecules from flavonoid class-this time in the terms of novel antifungal development. In this perspective, future studies might further enlighten their antifungal capacities especially by the in vivo experiments on different candidiasis models.

Author Contributions: Conceptualization, M.I., M.S., J.G., D.S. and I.C.F.R.F.; methodology, M.I, A.K., D.S.S. and R.C.C.; investigation, M.I., A.K., D.S.S. and R.C.C.; writing-original draft preparation, M.I., D.S.S. and R.C.C.; writing-review and editing J.G., M.S., A.K., D.S. and I.C.F.R.F.; supervision, I.C.F.R.F., D.S., J.G. and M.S.; funding acquisition, I.C.F.R.F., D.S. and M.S. All authors have read and agreed to the published version of the manuscript.

Funding: This research is funded by the Serbian Ministry of Education, Science and Technological Development [Contract No. 451-03-68/2020-14/200007]. The authors are grateful to the FEMS for providing FEMS Research and Training Grant [FEMS-GO-2017-015] to Marija Ivanov for her visit to Institute of Microbiology, University Hospital Lausanne and University Hospital Center, Rue du Bugnon 48, Lausanne, Switzerland. The authors are also grateful to the Foundation for Science and Technology (FCT, Portugal) for financial support through national funds FCT/MCTES to CIMO [UIDB /00690/2020] and to the national funding by FCT, P.I., through the institutional scientific employment program-contract for R. Calhelha's contract.

Institutional Review Board Statement: The study was conducted according to the guidelines of the ICH-GCP and local legislation and approved by the Ethics committee of Office for Human Research Protection, ZVEZDARA UNIVERSITY MEDICAL CENTER, Belgrade, Serbia, document issued 26 October 2016.

Informed Consent Statement: Informed consent was obtained from all subjects involved in the study. Data Availability Statement: The data presented in this study are available in this article.

Conflicts of Interest: The authors declare no conflict of interest.

\section{References}

1. Singh, D.K.; Tóth, R.; Gácser, A. Mechanisms of Pathogenic Candida Species to Evade the Host Complement Attack. Front. Cell. Infect. Microbiol. 2020, 10, 94. [CrossRef] [PubMed]

2. Sustr, V.; Foessleitner, P.; Kiss, H.; Farr, A. Vulvovaginal Candidosis: Current Concepts, Challenges and Perspectives. J. Fungi 2020, 6, 267. [CrossRef] [PubMed]

3. Vila, T.; Sultan, A.S.; Montelongo-Jauregui, D.; Jabra-Rizk, M.A. Oral Candidiasis: A Disease of Opportunity. J. Fungi 2020, 6, 15. [CrossRef] [PubMed]

4. Gonzalez-Lara, M.F.; Ostrosky-Zeichner, L. Invasive Candidiasis. Semin. Respir. Crit. Care Med. 2020, 41, 3-12. [CrossRef]

5. Dworecka-Kaszak, B.; Biegańska, M.J.; Dąbrowska, I. Occurrence of various pathogenic and opportunistic fungi in skin diseases of domestic animals: A retrospective study. BMC Vet. Res. 2020, 16, 248. [CrossRef]

6. Ciurea, C.N.; Kosovski, I.B.; Mare, A.D.; Toma, F.; Pintea-Simon, I.A.; Man, A. Candida and Candidiasis-Opportunism Versus Pathogenicity: A Review of the Virulence Traits. Microorganisms 2020, 8, 857. [CrossRef]

7. Jensen, R.H.; Astvad, K.M.; Silva, L.V.; Sanglard, D.; Jørgensen, R.; Nielsen, K.F.; Mathiasen, E.G.; Doroudian, G.; Perlin, D.S.; Arendrup, M.C. Stepwise emergence of azole, echinocandin and amphotericin B multidrug resistance in vivo in Candida albicans orchestrated by multiple genetic alterations. J. Antimicrob. Chemother. 2015, 70, 2551-2555. [CrossRef]

8. Bongomin, F.; Gago, S.; Oladele, R.O.; Denning, D.W. Global and Multi-National Prevalence of Fungal Diseases-Estimate Precision. J. Fungi 2017, 3, 57. [CrossRef]

9. Houšt', J.; Spížek, J.; Havlíček, V. Antifungal drugs. Metabolites 2020, 10, 106. [CrossRef]

10. Ćirić, A.; Petrović, J.; Glamočlija, J.; Smiljković, M.; Nikolić, M.; Stojković, D.; Soković, M. Natural products as biofilm formation antagonists and regulators of quorum sensing functions: A comprehensive review update and future trends. S. Afr. J. Bot. 2019, 120, 65-80. [CrossRef]

11. Smiljković, M.; Kostić, M.; Stojković, D.; Glamočlija, J.; Soković, M. Could Flavonoids Compete with Synthetic Azoles in Diminishing Candida albicans Infections? A Comparative Review Based on In Vitro Studies. Curr. Med. Chem. 2019, 26, 2536-2554. [CrossRef] [PubMed] 
12. Smiljković, M.; Stanisavljević, D.; Stojković, D.; Petrović, I.; Marjanović Vićentić, J.; Popović, J.; Golič Grdadolnik, S.; Marković, D.; Sanković-Babić, S.; Glamočlija, J.; et al. Apigenin-7-O-glucoside versus apigenin: Insight into the modes of anticandidal and cytotoxic actions. EXCLI J. 2017, 16, 795-807. [PubMed]

13. Zajdel, S.M.; Graikou, K.; Głowniak, K.; Chinou, I. Chemical analysis of Penstemon campanulatus (Cav.) Willd. antimicrobial activities. Fitoterapia 2012, 83, 373-376. [CrossRef] [PubMed]

14. Salazar-Aranda, R.; Granados-Guzmán, G.; Pérez-Meseguer, J.; González, G.M.; de Torres, N.W. Activity of polyphenolic compounds against Candida glabrata. Molecules 2015, 20, 17903-17912. [CrossRef]

15. Mail, M.H.; Himratul-Aznita, W.H.; Musa, M.Y. Anti-hyphal properties of potential bioactive compounds for oral rinse in suppression of Candida growth. Biotechnol. Biotechnol. Equip. 2017, 31, 989-999. [CrossRef]

16. Ozçelik, B.; Kartal, M.; Orhan, I. Cytotoxicity, antiviral and antimicrobial activities of alkaloids, flavonoids, and phenolic acids. Pharm. Biol. 2011, 49, 396-402. [CrossRef]

17. Gehrke, I.T.; Neto, A.T.; Pedroso, M.; Mostardeiro, C.P.; Da Cruz, I.B.; Silva, U.F.; Ilha, V.; Dalcol, I.I.; Morel, A.F. Antimicrobial activity of Schinus lentiscifolius (Anacardiaceae). J. Ethnopharmacol. 2013, 148, 486-491. [CrossRef]

18. Gao, M.; Wang, H.; Zhu, L. Quercetin assists fluconazole to inhibit biofilm formations of fluconazole-resistant Candida albicans in in vitro and in vivo antifungal managements of vulvovaginal candidiasis. Cell. Physiol. Biochem. 2016, 40, 727-742. [CrossRef]

19. Sekita, Y.; Murakami, K.; Yumoto, H.; Hirao, K.; Amoh, T.; Fujiwara, N.; Hirota, K.; Fujii, H.; Matsuo, T.; Miyake, Y. Antibiofilm and anti-inflammatory activities of houttuynia cordata decoction for oral care. Evid. Based Complement. Altern. Med. 2017, 2017, 2850947. [CrossRef]

20. Jun, J.E.; Lee, H.; Ko, H.J.; Woo, E.R.; Lee, D.G. Fungicidal effect of isoquercitrin via inducing membrane disturbance. BBA-Biomembranes 2015, 1848, 695-701.

21. Šiler, B.; Živković, S.; Banjanac, T.; Cvetković, J.; Nestorović Živković, J.; Ćirić, A.; Soković, M.; Mišić, D. Centauries as underestimated food additives: Antioxidant and antimicrobial potential. Food Chem. 2014, 147, 367-376. [CrossRef] [PubMed]

22. Han, Y. Rutin has therapeutic effect on septic arthritis caused by Candida albicans. Int. Immunopharmacol. $2009,9,207-211$. [CrossRef] [PubMed]

23. Johann, S.; Mendes, B.G.; Missau, F.C.; de Resende, M.A.; Pizzolatti, M.G. Antifungal activity of five species of Polygala. Braz. J. Microbiol. 2011, 42, 1065-1075. [CrossRef] [PubMed]

24. Kytidou, K.; Artola, M.; Overkleeft, H.S.; Aerts, J. Plant Glycosides and Glycosidases: A Treasure-Trove for Therapeutics. Front. Plant Sci. 2020, 11, 357. [CrossRef] [PubMed]

25. Shahzad, M.; Sherry, L.; Rajendran, R.; Edwards, C.A.; Combet, E.; Ramage, G. Utilising polyphenols for the clinical management of Candida albicans biofilms. Int. J. Antimicrob. Agents 2014, 44, 269-273. [CrossRef] [PubMed]

26. Lee, H.; Woo, E.R.; Lee, D.G. Apigenin induces cell shrinkage in Candida albicans by membrane perturbation. FEMS Yeast Res. 2018, 18, foy003. [CrossRef] [PubMed]

27. Alves, C.T.; Ferreira, I.C.; Barros, L.; Silva, S.; Azeredo, J.; Henriques, M. Antifungal activity of phenolic compounds identified in flowers from North Eastern Portugal against Candida species. Future Microbiol. 2014, 9, 139-146. [CrossRef]

28. Singh, B.N.; Upreti, D.K.; Singh, B.R.; Pandey, G.; Verma, S.; Roy, S.; Naqvi, A.H.; Rawat, A.K. Quercetin sensitizes fluconazoleresistant Candida albicans to induce apoptotic cell death by modulating quorum sensing. Antimicrob. Agents Chemother. 2015, 59, 2153-2168. [CrossRef]

29. Lewis, K. Riddle of biofilm resistance. Antimicrob. Agents Chemother. 2001, 45, 999-1007. [CrossRef]

30. Zagrean-Tuza, C.; Mot, A.C.; Chmiel, T.; Bende, A.; Turcu, I. Sugar matters: Sugar moieties as reactivity-tuning factors in quercetin O-glycosides. Food Funct. 2020, 11, 5293-5307. [CrossRef]

31. Ivanov, M.; Kannan, A.; Stojković, D.; Glamočlija, J.; Golič Grdadolnik, S.; Sanglard, D.; Soković, M. Revealing the astragalin mode of anticandidal action. EXCLI J. 2020, 19, 1436-1445. [PubMed]

32. Brown, A.R.; Ettefagh, K.A.; Todd, D.; Cole, P.S.; Egan, J.M.; Foil, D.H.; Graf, T.; Schindler, B.; Kaatz, G.; Cech, N. A Mass Spectrometry-Based Assay for Improved Quantitative Measurements of Efflux Pump Inhibition. PLoS ONE 2015, 10, e0124814. [CrossRef] [PubMed]

33. Yan, X.; Qi, M.; Li, P.; Zhan, Y.; Shao, H. Apigenin in cancer therapy: Anti-cancer effects and mechanisms of action. Cell Biosci. 2017, 7, 1-16. [CrossRef] [PubMed]

34. Matsuo, M.; Sasaki, N.; Saga, K.; Kaneko, T. Cytotoxicity of flavonoids toward cultured normal human cells. Biol. Pharm. Bull. 2005, 28, 253-259. [CrossRef] [PubMed]

35. Hadrich, F.; Sayadi, S. Apigetrin inhibits adipogenesis in 3T3-L1 cells by downregulating PPAR $\gamma$ and CEBP- $\alpha$. Lipids Health Dis. 2018, 17, 95. [CrossRef] [PubMed]

36. Horinaka, M.; Yoshida, T.; Shiraishi, T.; Nakata, S.; Wakada, M.; Nakanishi, R.; Nishino, H.; Matsui, H.; Sakai, T. Luteolin induces apoptosis via death receptor 5 upregulation in human malignant tumor cells. Oncogene 2005, 24, 7180-7189. [CrossRef] [PubMed]

37. Amado, N.G.; Predes, D.M.; Fonseca, B.F.; Cerqueira, D.M.; Reis, A.H.; Dudenhoeffer, A.C.; Borges, H.L.; Mendes, F.A.; Abreu, J.G. Isoquercitrin suppresses colon cancer cell growth in vitro by targeting the Wnt/ $\beta$-catenin signaling pathway. J. Biol. Chem. 2014, 289, 35456-35467. [CrossRef]

38. EUCAST (European Committee on Antibiotic Susceptibility). Method for Determination of Minimal Inhibitory Concentration (MIC) by Broth Dilution of Fermentative Yeasts; Discussion document E. Dis. 7.1; European Society of Clinical Microbiology and Infectious Diseases: Munich, Germany, 2002. 
39. Smiljkovic, M.; Matsoukas, M.T.; Kritsi, E.; Zelenko, U.; Grdadolnik, S.G.; Calhelha, R.C.; Ferreira, I.C.F.R.; Sankovic-Babic, S.; Glamoclija, J.; Fotopoulou, T.; et al. Nitrate Esters of Heteroaromatic Compounds as Candida albicans CYP51 Enzyme Inhibitors. ChemMedChem 2018, 13, 251-258. [CrossRef]

40. Sanglard, D.; Ischer, F.; Calabrese, D.; Majcherczyk, P.A.; Bille, J. The ATP binding cassette transporter gene CgCDR1 from Candida glabrata is involved in the resistance of clinical isolates to azole antifungal agents. Antimicrob. Agents Chemother. 1999, 43, 2753-2765. [CrossRef]

41. Lohberger, A.; Coste, A.T.; Sanglard, D. Distinct roles of Candida albicans drug resistance transcription factors TAC1, MRR1, and UPC2 in virulence. Eukaryot. Cell. 2014, 13, 127-142. [CrossRef]

42. Guimaraes, R.; Barros, L.; Duenas, M.; Calhelha, R.C.; Carvalho, A.M.; Santos-Buelga, C.; Queiroz, M.J.; Ferreira, I.C.F.R. Nutrients, phytochemicals and bioactivity of wild Roman chamomile: A comparison between the herb and its preparations. Food Chem. 2013, 136, 718-725. [CrossRef] [PubMed] 